\title{
Reduction of emissions by using various syngases with different injection strategies under premixed combustion mode
}

\author{
Kurji $H^{a b^{*}}$, Aniekan Okon ${ }^{a}$,Valera-Medina ${ }^{a}$, Cheng-Tung $C^{c}$ \\ ${ }^{a}$ Cardiff University, Queen's Building, Cardiff, United Kingdom. \\ ${ }^{\mathrm{b}}$ Kerbela University, College of Engineering, Mechanical Department, Kerbela, Iraq \\ ${ }^{\mathrm{c}}$ Faculty of Mechanical Engineering, Universiti Teknologi, Malaysia \\ "KurjiHJ@cardiff.ac.uk
}

\begin{abstract}
Increasing interest in alternative fuels for gas turbines has motivated research in gaseous fuels other than natural gas. Methane enriched with hydrogen or diluted with carbon dioxide are of considerable interest. The latter seems quite relevant for development of technologies such as oxyfuel combustion for carbon capture and storage in order to control temperatures in the combustion chamber. Thus, this paper presents an experimental study on the combustion of methanecarbon dioxide mixtures at atmospheric conditions. Gas mixtures have been examined by using different levels of premixing with different injection strategies with and without swirl and with and without central injection. A $20 \mathrm{~kW}$ burner has been used to investigate the flame stability and emissions performance by using these blends to examine the effect of $\mathrm{CO} 2$ addition. The burner configuration consisted of a centre body with an annular, premixed gas/air jet introduced through five, $60^{\circ}$ swirl vanes. A TESTO 350XL gas analyzer was used to obtain NOx and CO emission trends to characterize all the injection regimes whilst using different fuel blends. $\mathrm{CH}$ chemiluminescence diagnostics was also used and correlated to the levels of emissions produced during the trials. The resulting images were analysed using Photron FASTCAM PFV ver 2.4.1.1 software and MATLAB R2015a. CO2 dilution decreased flame stability and operability range. The introduction of $\mathrm{CO} 2$ reduces temperatures in the combustion zone thus causing a reduction in emissions of nitrous oxides across all equivalence ratios. $\mathrm{CO}$ emissions also decreased with a limited (15\%) $\mathrm{CO} 2$ addition. In terms of injection regimes, the outer purely premixed injection regime has lower NOx and $\mathrm{CO}$, as expected. $\mathrm{CH}$ chemiluminescence distribution indicated that pure methane with central injection produced high fluctuation in $\mathrm{CH}$ production. The use of central premixed injection produces the most chaotic $\mathrm{CH}$ production case, possibly as a consequence of production of radicals in the central recirculation zone.
\end{abstract}

Keywords- Stability; combustion; Gas Turbine; emissions; heat release

\section{INTRODUCTION}

Premixed combustion is the most used strategy to decrease undesirable emissions in gas turbines. In premixed systems, fuel and air are mixed earlier to the combustion chamber to promote mixing, combustion efficiency, uniform temperatures and low NOx $[1,2]$. When working in a premixed mode, many stability problems can arise $[3,4]$. Thus, the use of combustion devices needs detailed characterization of performance and emissions to ensure minimal impact to the environment and equipment integrity.

In various combustion devices, swirling flames are used to increase fuel/air mixing, increase flame burning strength and stabilize the flame [5]. Swirling flows are defined as flows undergoing simultaneous axial-tangential vortex motion. This flow motion can be made using swirl vanes or several different techniques [6]. The main required characteristic of swirl combustors is the development of separated reverse flow zones and central recirculation zones capable of recycling hot chemically active reactants to substantially improve flame stability [4]. The swirl number is one of the main factors used to characterize swirling flows. It is defined as the ratio of axial flux of swirl momentum divided by axial flux of axial momentum [2].

Important research has focused on the effect of swirl on flame stability, combustion efficiency and emissions performance. Different groups have performed emissions measurements using swirl combustor of various configurations. Khalil [7] measured the emissions of gaseous and liquid fuels using a fuel-flexible swirl combustor. Chong and Hochgreb used an axial swirl burner to study the flow field [8] and emissions of liquid swirl flames [9]. Nemitallah [10] examined the oxy-combustion flame in diffusional mode and characterized the emissions using a swirl burner. The fuel used was methane containing carbon monoxide $(\mathrm{CO})$ and oxygen $(\mathrm{O} 2)$. Reddy [11] used the exhaust gas recirculation idea to reduce thermal NOx for biodiesel and half biodiesel/diesel mixtures with swirling flames. It was informed that the blending of biodiesel with fossil fuel facilitated a decrease in emissions. The geometry of the burner and swirler also affected the emissions. Bhoi [12] measured the emissions of a $150 \mathrm{~kW}$ producer gas-fired premixed burner. The outcome shows that NOx emissions rise with swirl angle while $\mathrm{CO}$ emissions are independent of swirl angle. Non-intrusive optical measurement techniques can also be used to estimate emissions and flame patterns, as they give improved flame measurement ability which results from the undisturbed flow field and non-interaction with the flame front. Among these methods, chemiluminescence imaging of reactive combustion species (e.g. $\mathrm{OH}$ and $\mathrm{CH}$ ) has been shown to provide fundamental measures of flame structure [13] and heat release [14]. 
In terms of alternative fuels, the main goal of introducing $\mathrm{CO} 2$ into the gas turbine combustor is the reduction of $\mathrm{NOx}$ emissions. This is completed by cooling the flame, thus the Zeldovich mechanism can be reduced [15]. Previous experimental and numerical studies have studied the impact of diluting Syngas fuels with many additives, including carbon dioxide, nitrogen and steam $[16,17]$. In the larger part, these studies concentrate on fundamental characteristics of the combustion process. However, the work by Lee et al. [16] essentially examined the influence of diluting the premix fuel on the emission of NOx and $\mathrm{CO}$ from a model gas turbine. They showed that reducing $\mathrm{NOx}$ per unit power is logarithmically associated to the heat capacity of the total diluent added. Since carbon dioxide has a maximum heat capacity than steam or nitrogen, a smaller mass flow rate is necessary for a comparable reduction in NOx. Furthermore, the use of $\mathrm{CO} 2$ from carbon capture and storage facilities could decrease costs as well as capture equipment further downstream the combustion zone [16]. Meanwhile, the CO2 injected through the premixed blend will reduce the reaction rate, thus reducing the temperature. The high temperature of the $\mathrm{CO} 2$ in the $\mathrm{CRZ}$ will ensure a faster chemical reaction of the diluted reactants, thus allowing a stable regime with low NOx and CO. Synthesis gas, also known as syngas, created from gasification processes is regarded as one of the promising alternative energies due to its clean fuel characteristics. Synthesis can be produced via gasification of several feedstock, including coal, biomass and solid waste. The use of syngas as fuel source can reduce $\mathrm{CO} 2, \mathrm{NOx}$ and other pollutants [17]. One sample of syngas use is in Integrated Gasification Combined Cycle (IGCC) power plants where syngas fuel is combusted in gas turbines to produce power and electricity [18, 19]. Regardless of the proven feasibility of syngas, the challenge that syngases face is the variation in their composition due to different feedstock and production procedures. Moreover, the shortage of understanding of the combustion characteristics of syngases poses difficulty in the design of syngas-specific systems and combustors [20], thus making flexible designs a challenge that requires further research.

Therefore, the present work presents an experimental study on the combustion of methane-carbon dioxide mixtures at atmospheric conditions by using a $20 \mathrm{~kW}$ generic burner. Gas mixtures have been examined by using different levels of premixing with different injection strategies with and without swirl and with and without central injection. A TESTO 350XL gas analyser was used to obtain NOx and CO emissions to characterize all the injection regimes whilst using different fuel blends. Moreover, $\mathrm{CH}$ chemiluminescence diagnostics was examined and correlated to the levels of emissions produced during the trials.

\section{EXPERIMENTAL SETUP}

\section{A. Swirl burner and flow delivery system}

An axial swirl burner was utilised to establish continuous swirling flames. The schematic of the swirl flame burner and the flow delivery system is shown in Figure.1. while the placement position of the swirler at the burner outlet is shown in Figure . 2. The swirl burner used in this experiment consists of an axial swirler and a circular stainless steel tube placed as shown in Figure.1. It consists of five straight swirl vanes with a thickness of $1.5 \mathrm{~mm}$. The swirler vanes are fixed at the angle of $60^{\circ}$ from the axial centerline axis. The outer diameter of the swirler is $50 \mathrm{~mm}$, while the swirler hub diameter is $10 \mathrm{~mm}$, table 1 and Figure 3. The geometrical swirl number, $\mathrm{S}$, is based on the following equation [21],

$$
S_{N}=\frac{2}{3}\left[\frac{1-\left(\frac{D_{h}}{D_{s}}\right)^{3}}{1-\left(\frac{D_{h}}{D_{s}}\right)^{2}}\right] \tan \theta
$$

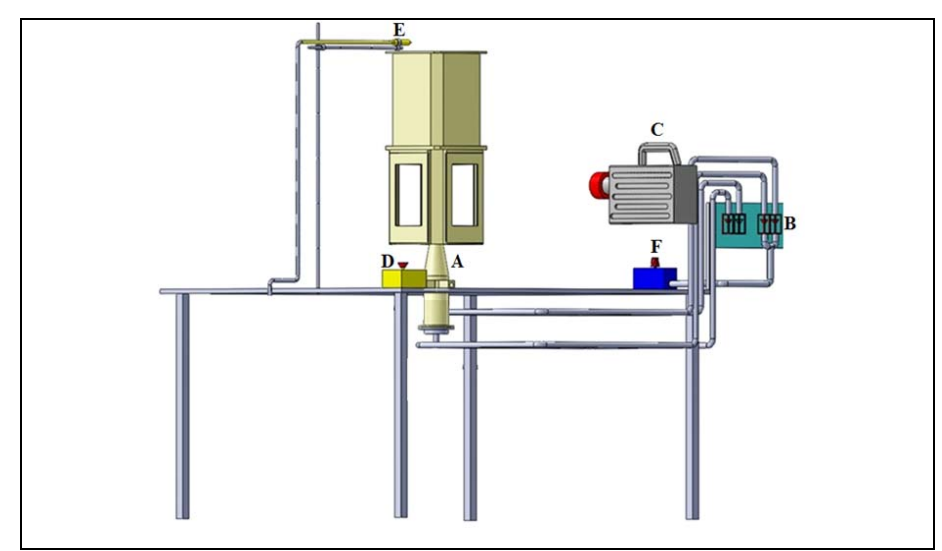

Fig. 1. Generic swirl burner with Accessories. A - Swirl Burner; B Rotameters; C - High Speed Camera; D - Emergency button; E - Pilot Burners; F - Air Regulater.

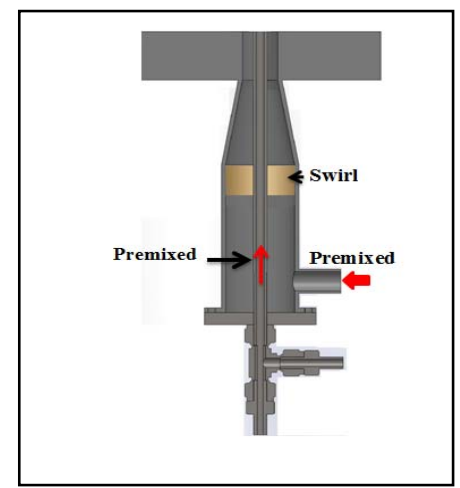

Fig. 2. Example of a Schematic burner and swirler.

Where $D_{h}$ and $D_{s}$ represent the swirler hub diameter and the swirler diameter respectively, and $\theta$ is the vane angle orientation from the centerline axis. The Swirl number was calculated at 1.2. This strong swirl enables the formation of a recirculation zone that recirculates hot products and assists in flame stabilisation [22]. Two modes of injection were used, one through the centre via a central injector, and one through the outer, main premixed zone, Figure.2. For flow delivery, methane and carbon dioxide gases were supplied and regulated via Platon and NGX mass flow meters with an accuracy of $\pm 1.25 \%$, whilst air was supplied and regulated via 
Platon and NGX mass flow meters with an accuracy of $\pm 5 \%$ and $\pm 1.25 \%$, respectively.

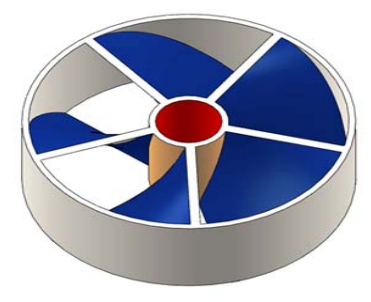

Fig. 3. : Axial swirler .

TABLE I. GEOMETRY OF AXIAL SWIRL FLAME BURNER AND RELEVANT BURNER DIMENSIONS [MM].

\begin{tabular}{|c|c|}
\hline \multicolumn{2}{|c|}{ Air swirler } \\
\hline Material & Stainless steel \\
\hline Type & Axial, straight vane \\
\hline Swirl number, SN & 1.2 \\
\hline Swirl angle, $\theta\left(^{\circ}\right)$ & 60 \\
\hline Number of blades & 5 \\
\hline Blade thickness, $t(\mathrm{~mm})$ & 1.5 \\
\hline \multicolumn{2}{|c|}{ Burner wall } \\
\hline Material & Stainless steel \\
\hline Width (mm) & 118 \\
\hline Height (mm) & 410 \\
\hline \multicolumn{2}{|c|}{ Burner geometry } \\
\hline Burner outer diameter, Ds (mm) & 50 \\
\hline Burner central diameter, $\mathrm{Dh}(\mathrm{mm})$ & 10 \\
\hline $\begin{array}{l}\text { Burner inner central diameter, } \mathrm{d} \\
(\mathrm{mm})\end{array}$ & 6 \\
\hline
\end{tabular}

Gases and air for both central and outer parts were premixed in separate tubes to ensure adequate mixing before entering the burner. A pilot ignitor was used to ignite the flame as shown in Figure .1. The combustion chamber is of rectangular form and has four quartz windows, giving full optical access to the combustion zone. The width and the height of the combustion chamber is $118 \mathrm{~mm}$ and $410 \mathrm{~mm}$ respectively. Details of the burner geometry are shown in Table 1.

\section{B. Operating conditions}

$\mathrm{CH} 4$ was blended with $\mathrm{CO} 2$ as diluent impacts were investigated. Table 2 shows all tested blends. The effect of $\mathrm{CO} 2$ as diluent on the emissions was investigated by incrementally adding $\mathrm{CO} 2$ from $0 \%$ to $15 \%$ and $30 \%$. The blends for all cases were supplied by cylinders that contained $\mathrm{CO} 2$ already mixed with $\mathrm{CH} 4$ at the required percentages, table 2. Various injection strategies were followed to observe how the increment of central and/or outer injection affected the flame and reduce/increase NOx and CO emissions, Table 3. A TESTO 350XL gas analyser was used to acquire NOx and $\mathrm{CO}$ emissions to characterize all the injection regimes while using different fuel mixtures. $\mathrm{CH}$ chemiluminescence diagnostics was examined and correlated to the stability of each case. It was not possible to work under lean conditions using B2 and B3 as blow off would occur. Thus, rich conditions were imposed for these blends.
TABLE II. BLEND MIXTURES COMPOSITION (VOL. \%)

\begin{tabular}{ccc}
\hline Mixture & CH4 & CO2 \\
\hline B1 & 100 & 0 \\
B2 & 85 & 15 \\
B3 & 70 & 30 \\
\hline
\end{tabular}

TABLE III. INJECTION STRATEGIES

\begin{tabular}{|c|c|c|}
\hline strategies & Outer injection & Central injection \\
\hline S1 & YES Premixed & YES Premixed \\
\hline S2 33 & YES Premixed & NO \\
\hline S & YES Premixed & YES Diffusion \\
\hline
\end{tabular}

C. Emissions measurements

Measurements of post combustion emissions were performed using a TESTO 350-XL gas analyzer at approximately 500 $\mathrm{mm}$ downstream of the burner outlet. The sampling probe was placed $10 \mathrm{~mm}$ inside from the exit plane. The measured emissions include NOx and $\mathrm{CO}$ with the measurement range of 0-1000 ppm and 0-10,000 ppm, respectively. The emissions readings from the gas analyser are reported in wet basis with the uncertainty of $\pm 5 \% \mathrm{ppm}$ for $\mathrm{NOx}, \pm 5 \% \mathrm{ppm}$ for $\mathrm{CO}$. Measurements were taken 1 minute after the readings have become stabilized.

\section{Calculation method}

Stoichiometric combustion reactions for gas mixtures of methane and methane - carbon dioxide can be written as follows,

$$
\begin{gathered}
\mathrm{CH} 4+2 \cdot(\mathrm{O} 2+3.76 \cdot \mathrm{N} 2)=\mathrm{CO} 2 \\
+2 \cdot \mathrm{H} 2 \mathrm{O}+2 \cdot 3.76 \cdot \mathrm{N} 2 \\
\mathrm{CH} 4+\mathrm{k} \cdot \mathrm{CO} 2+2 \cdot(\mathrm{O} 2+3.76 \cdot \mathrm{N} 2)= \\
(k+1) \cdot \mathrm{CO} 2+2 \cdot \mathrm{H} 2 \mathrm{O}+2 \cdot 3.76 \cdot \mathrm{N} 2
\end{gathered}
$$

Where $\mathrm{k}$ is the molar fraction ratios of added gas in methane, $\mathrm{k}=X_{\mathrm{CO} 2} / X_{\mathrm{CH} 4} \triangleright$ Stoichiometric air fuel ratios (AFR) of methane- carbon dioxide and methane are calculated as,

$$
\begin{gathered}
\operatorname{AFR}_{s t}^{\mathrm{CH}_{4}}=\frac{2 \cdot\left(M_{\mathrm{O}_{2}}+3.76 \cdot M_{N_{2}}\right)}{M_{C H_{4}}} \\
\mathrm{AFR}_{s t}^{\mathrm{CH}_{4}-\mathrm{CO}_{2}}=\frac{2 \cdot\left(M_{\mathrm{O}_{2}}+3.76 \cdot M_{N_{2}}\right)}{M_{\mathrm{CH}_{4}}+k \cdot M_{\mathrm{CO}_{2}}}
\end{gathered}
$$

The mass flow rate of the gas mixture and air was measured and the equivalence ratio calculated from the formula,

$$
\mathrm{ER}=\frac{\mathrm{AFR}_{\text {st }}}{\dot{m}_{\text {air }} / \dot{m}_{\text {fuel }}}
$$

\section{E. CHEMILUMINESCENCE}

$\mathrm{CH}$ Chemiluminescence fluctuation rates associated to flame heat release were measured for all different injection regimes, equivalence ratios, blends and Swirl conditions 
using a Photron High Speed Camera and a Hamamatsu Intensifier coupled with a UV lens and a $420 \pm 10 \mathrm{~nm}, 85$ transmissivity optical filter. Repetition rates were set at 60 $\mathrm{Hz}$ to provide an overview of $\mathrm{CH}$ fluctuations for each case. The resulting images were analysed using a Photron FASTCAM PFV ver 2.4.1.1 software and MATLAB R2015a.

\section{RESULTS AND DISCUSSION}

\section{A. NOx emissions}

Figure 4 gives the variation in the level of NOx emissions as a function of equivalence ratio with different injection regimes with and without swirl for all different blends. Overall, all equivalence ratio tested showed a decreasing trend as the $\mathrm{CO} 2$ diluent ratio increases from 0 to $30 \%$. The lower NOx can be attributed to the thermal effects of $\mathrm{CO} 2$ dilution. The thermal effect decreases the flame temperature and thus the thermal NO [16]. CO2 diluent reduces the adiabatic temperature due to its higher specific heat, which would result in a significant decrease in overall burning rate via absorption of heat from the combustion process [23]. Lowering the flame temperature caused less NOx to be emitted, concurring with the thermal NOx formation mechanism [16]. Addition of diluent to the air stream also caused a corresponding decrease in oxygen mole fraction. Consequently, the flame temperature and the mole fractions of $\mathrm{H}, \mathrm{O}$, and $\mathrm{OH}$ radicals were reduced. For the chemical effect, addition of diluents decreased $\mathrm{N}$ and $\mathrm{HCN}$ mole fractions and subsequently reduced the prompt NO [24]. In terms of injection strategies an outer injection regime with swirling vanes and no central injection (S2) has produced the cleanest profiles, as expected. For the other cases (S1, S3) the fuel is introduced through the central injector; and as such it has only an axial velocity component that would lead to a decrease in the swirl number. For all mixtures, the trend is similar with low equivalence ratios showing the lowest NOx. Surprisingly, B3 with and without swirl basically produced the same NOx results. As previously stated, this is a consequence of the increase in $\mathrm{CO} 2$ diluent, thus reduction of thermal NOx formation. Further analyses will be carried out regarding $\mathrm{CO}$ for this blend. For pure methane, (B1), emissions are comparatively higher across all ranges of equivalence ratios, as expected [26].

\section{B. CO emissions}

In addition, $\mathrm{CO}$ emissions are influenced by the injection mechanism, equivalence ratios and fuel blends at different operating conditions. Figure 5 presents the $\log$ form of $\mathrm{CO}$ emissions as a function of equivalence ratios for all mixtures using different injection regimes and with two swirling cases. Overall, all tested equivalence ratios showed a decreasing trend as the $\mathrm{CO} 2$ diluent ratio increases. However, the best trends was obtained using B2 (85\% CH4-15\% CO2) which produced the lowest concentration of $\mathrm{CO}$. The high production of $\mathrm{CO}$ with $\mathrm{B} 1$ is due to the incomplete combustion of pockets of fuels. This could also be attributed to the short residence time when the system runs without swirl, so the CO formed in the combustion zone has less time to completely convert to $\mathrm{CO} 2$.

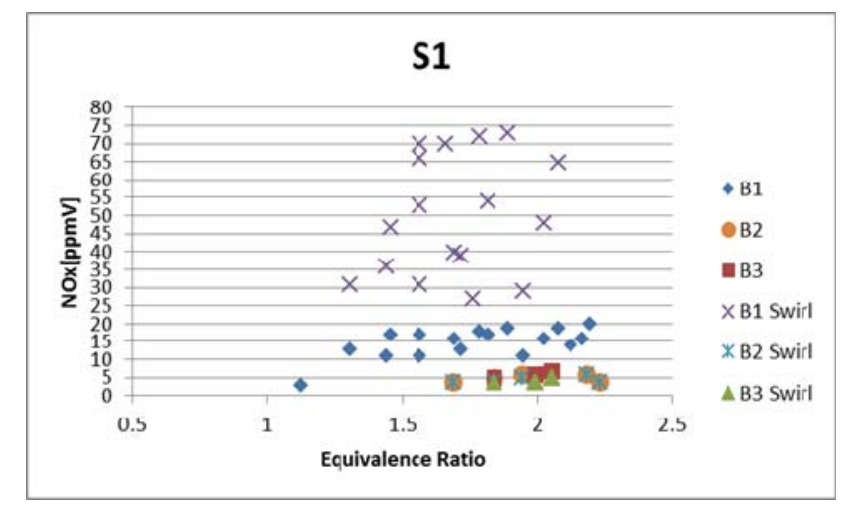

(a)

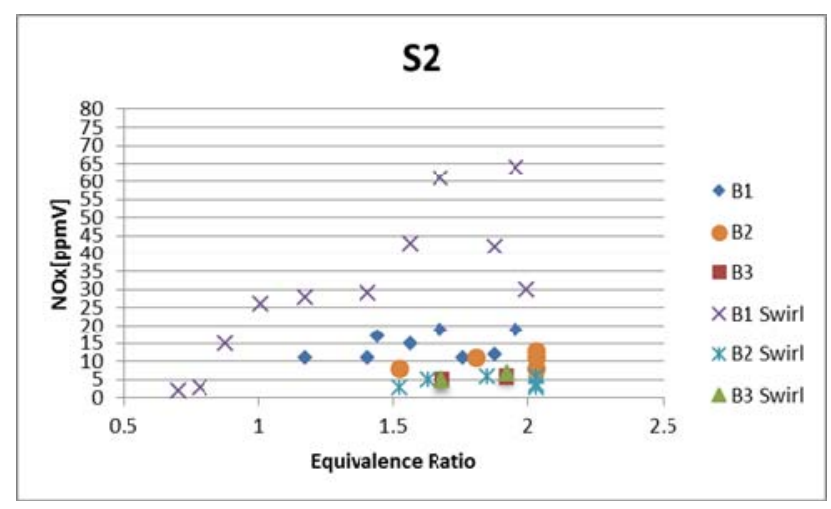

(b)

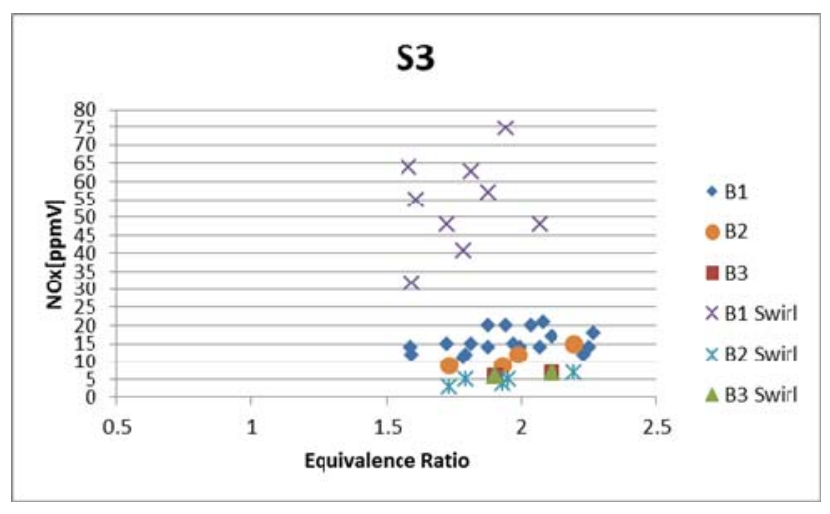

(c)

FIG 4. NOx exhaust gas concentration (dry) as a function of equivalence ratio for B1, B2 and B3 for different injection regimes with Swirl and without Swirl.

Furthermore, the low flame temperature under rich conditions prohibits the conversion of $\mathrm{CO}$ into stable species of $\mathrm{CO} 2$ [27]. Thus, an increase in equivalence ratio resulted in an augmentation of $\mathrm{CO}$ formation by increasing the quantity of gas. Swirling flows with their coherent structures enhance good mixing that results in the reduction of $\mathrm{NOx}$ and $\mathrm{CO}$ as shown in Figures 4 and 5. Interestingly, B2 with swirl showed the lowest CO profiles. Moreover, similar to NOx formation, $\mathrm{B} 3$ produces similar $\mathrm{CO}$ results with and without swirl. A 
slight increase of $\mathrm{CO} 2$ in the blend seems to be acting as a promoter of better combustion, reducing the competition of reacting species for oxygen. However, this phenomenon stops at higher $\mathrm{CO} 2$ concentrations which lead to combustion only at the tip of the burner. The latter is confirmed by the production of the same quantities of NOx (i.e. same temperature), low flame resistance (i.e. limited equivalence ratios in the rich region) and same $\mathrm{CO}$ emissions (i.e. combustion only in a small section of the combustion zone), all evidence that combustion takes place only at the tip of the burner outlet.

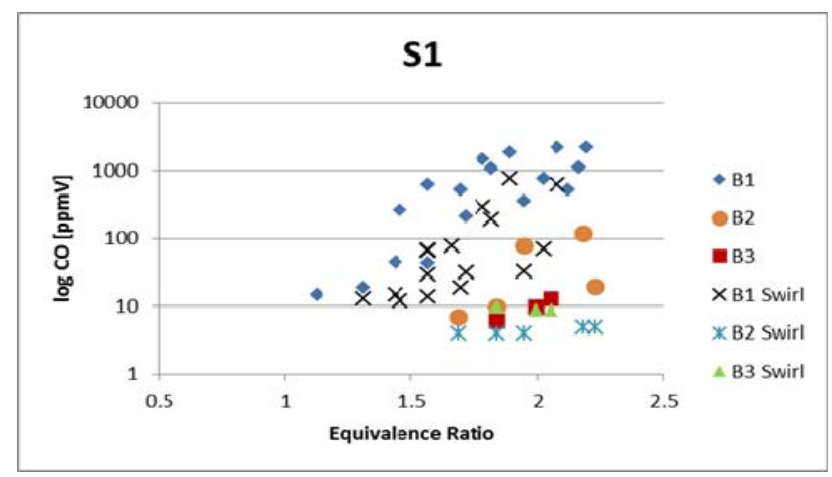

(a)

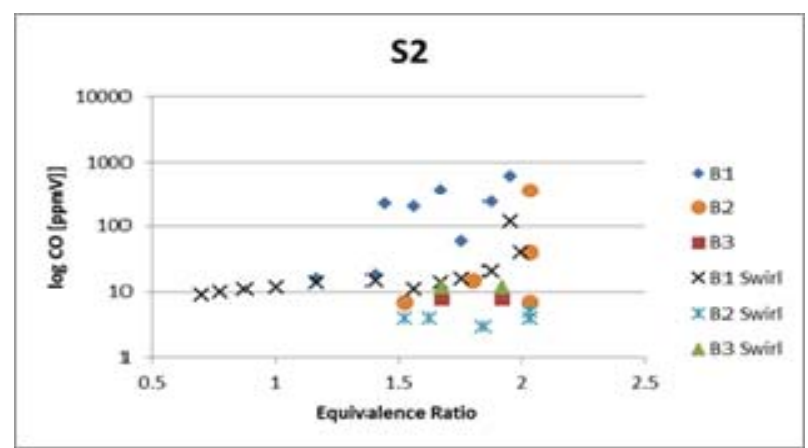

(b)

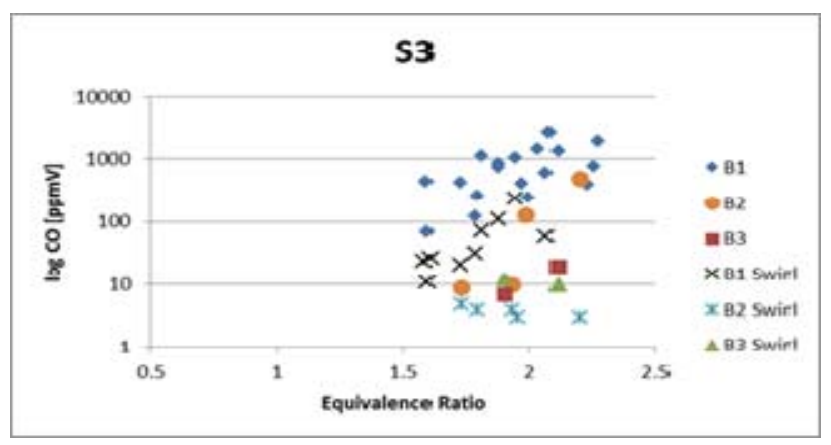

(c)

FIG 5. CO exhaust gas concentration (dry) as a function of equivalence ratio for B1, B2 and B3 for different injection regimes with Swirl and without Swirl.

\section{Heat release}

Heat release fluctuations in the aforementioned operating conditions were also examined. Figure 6 shows gain $(\mathrm{CH})^{\prime} /(\mathrm{CH})$ as a function of time for B1, B2 and B3 for all different injection regimes with and without swirl. Different equivalence ratios were used. Comparison between blends was performed to observe the progression of $\mathrm{CH}$ radicals at different conditions. Results clearly showed a large gain for B1-S1 and B1-S3, likely a consequence of poor mixing and high reactivity compared to the blends.

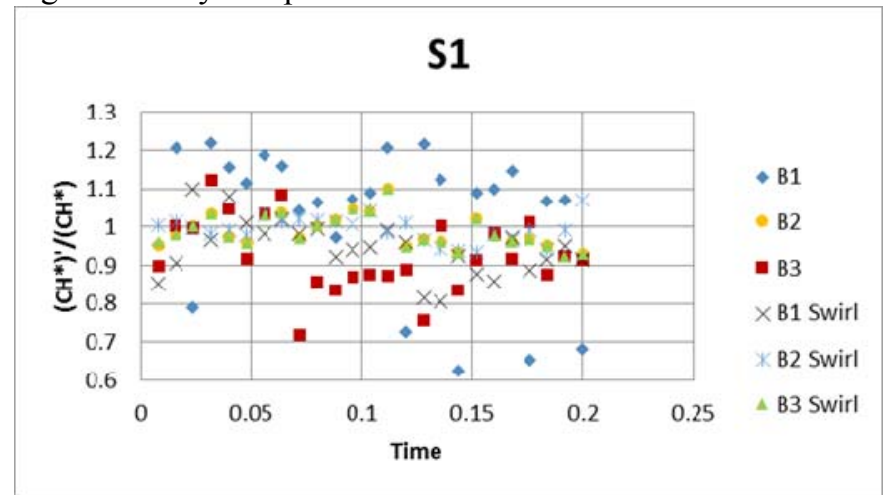

(a)

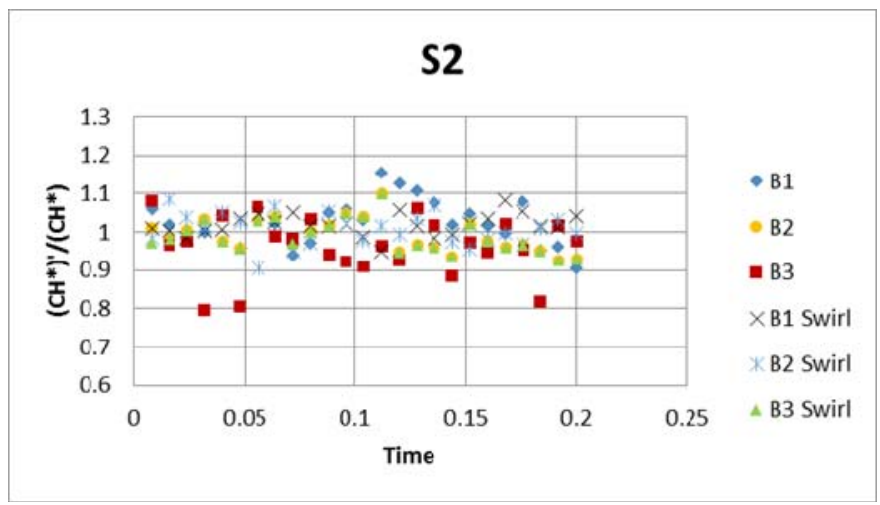

(b)

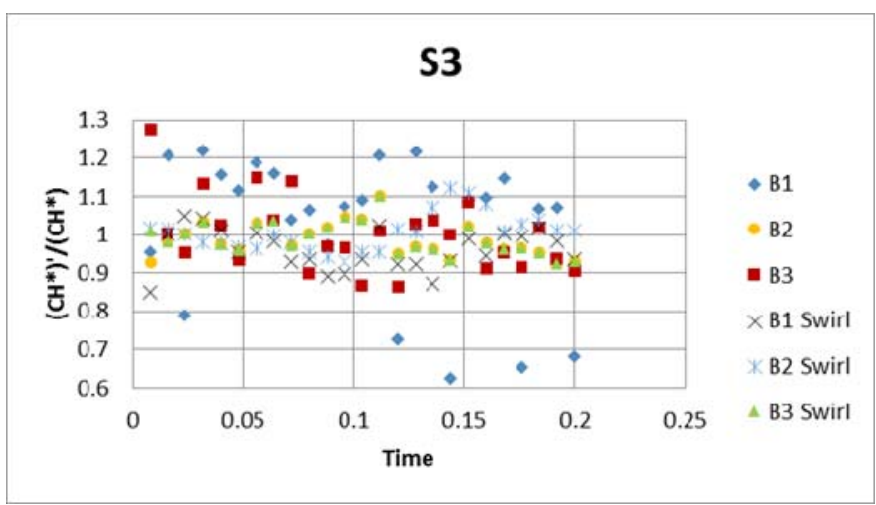

(c)

FIG 6. Gain as a function of time for B1, B2 and B3 for different injection regimes with Swirl and without Swirl (a- $\Phi=1.8$, b- $\Phi=1.6$, c- $\Phi=1.9$ ). 
S2 shows the most stable conditions, as expected. However, an unexpected result is the higher stability of the diffusive central injection compared to the premixed central injection. This has been theorized as a consequence of the increased reaction of radicals caused by more oxygen in the central recirculation zone where the central premixed injection is discharging its premixed blend. Since the central recirculation zone is a high complex, quasi-chaotic recirculation region formed by the collision of vortices of all sizes, the injection into the latter will produce high fluctuations of radicals, as observed. However, this does not improve emissions reduction and barely augments flame stability, as demonstrated in the previously stated results.

\section{CONCLUSIONS}

An experimental study on the combustion of methane-carbon dioxide mixtures at atmospheric conditions was carried out. Gas mixtures have been examined by using different levels of premixing with different injection strategies with and without swirl and with and without central injection. Results showed that the introduction of limited amounts of CO2 (15\%) have controlled reaction rates and temperatures in the combustion zone, thus causing a reduction in emissions with a decrease in flame stability at low equivalence ratios. Further dilution leads to even poorer combustion and flame extinction just above the burner tip. $\mathrm{CH}$ chemiluminescence distribution indicated that $\mathrm{B} 1-\mathrm{S} 1$ and $\mathrm{B} 1-\mathrm{S} 3$ have higher $\mathrm{CH}$ radical fluctuations, as the production of $\mathrm{CH}$ is greater but less controlled when compared to B1-S2. The use of central premixed injection produces the most chaotic $\mathrm{CH}$ production case, possibly as a consequence of production of radicals in a highly chaotic region such as the central recirculation zone.

\section{Acknowledgment}

The author thanks the Iraqi government for the support of his studies through a $\mathrm{PhD}$ scholarship. Finally, the group thanks the workshop staff at Cardiff University for their support.

\section{References}

[1] Y. Huang and V. Yang, "Effect of swirl on combustion dynamics in a lean-premixed swirl-stabilized combustor," Proc. Combust. Inst., vol. 30, no. 2, pp. 1775-1782, 2005.

[2] A. H. Lefebvre, Gas turbine combustion. CRC press, 1998.

[3] R. Sankaran, E. R. Hawkes, J. H. Chen, T. Lu, and C. K. Law, "Direct numerical simulations of turbulent lean premixed combustion," in Journal of Physics: conference series, vol. 46, no. 1, p. 38. 2006.

[4] A. K. Gupta, D. G. Lilley, and N. Syred, "Swirl flows," Tunbridge Wells, Kent, England, Abacus Press. 1984, 488 p., vol. 1, 1984.

[5] Z. H. Chen, G. E. Liu, and S. H. Sohrab, "Premixed flames in counterflow jets under rigid-body rotation," Combust. Sci. Technol., vol. 51, no. 1-3, pp. 39-50, 1987.

[6] N. Shelil, A. Bagdanavicius, N. Syred, A. Griffiths, and P. Bowen, "Premixed swirl combustion and flash back analysis with hydrogen/methane mixture," in 48th AIAA Aerospace Sciences Meeting, Orlando, USA, ref. AIAA-2010-1169, 2010.

[7] A. E. E. Khalil and A. K. Gupta, "Fuel flexible distributed combustion for efficient and clean gas turbine engines," Appl. Energy, vol. 109, pp. 267-274, 2013.

[8] C. T. Chong and S. Hochgreb, "Flow field of a model gas turbine swirl burner," in Advanced Materials Research, vol. 622, pp. 1119-1124, 2013.

[9] C. T. Chong and S. Hochgreb, "Spray flame study using a model gas turbine swirl burner," in Applied Mechanics and Materials, vol. 316, pp. 17-22, 2013.

[10] M. A. Nemitallah and M. A. Habib, "Experimental and numerical investigations of an atmospheric diffusion oxy-combustion flame in a gas turbine model combustor," Appl. Energy, vol. 111, pp. 401-415, 2013.

[11] V. M. Reddy, P. Biswas, P. Garg, and S. Kumar, "Combustion characteristics of biodiesel fuel in high recirculation conditions," Fuel Process. Technol., vol. 118, pp. 310-317, 2014

P. R. Bhoi and S. A. Channiwala, "Emission characteristics and axial flame temperature distribution of producer gas fired premixed burner," biomass and bioenergy, vol. 33, no. 3, pp. 469-477, 2009.

[13] B. Taupin, G. CABOT , G. Martins, D. Vauchelles, and A. Boukhalfa, "Experimental study of stability, structure and $\mathrm{CH}$ chemiluminescence in a pressurized lean premixed methane turbulent flame," Combust. Sci. Technol., vol. 179, no. 1-2, pp. 117-136, 2007.

[14] L. C. Haber, U. Vandsburger, W. R. Saunders, and V. K. Khanna, "An experimental examination of the relationship between chemiluminescent light emissions and heat-release rate under non-adiabatic conditions," 2001 .

[15] J. Warnatz, U. Maas, and R. W. Dibble, Combustion, vol. 26, no. 5. Springer, 1999.

[16] M. C. Lee, S. Bin Seo, J. Yoon, M. Kim, and Y. Yoon, "Experimental study on the effect of $\mathrm{N} \mathrm{2,CO} \mathrm{2,} \mathrm{and} \mathrm{steam} \mathrm{dilution} \mathrm{on} \mathrm{the} \mathrm{combustion}$ performance of $\mathrm{H} 2$ and CO synthetic gas in an industrial gas turbine," Fuel, vol. 102, pp. 431-438, 2012.

[17] H. J. Burbano, J. Pareja, and A. A. Amell, "Laminar burning velocities and flame stability analysis of $\mathrm{H} 2 / \mathrm{CO} /$ air mixtures with dilution of $\mathrm{N} 2$ and CO 2," Int. J. Hydrogen Energy, vol. 36, no. 4, pp. 3232-3242, 2011 .

[18] J. Fu, C. Tang, W. Jin, L. D. Thi, Z. Huang, and Y. Zhang, "Study on laminar flame speed and flame structure of syngas with varied compositions using OH-PLIF and spectrograph," Int. J. Hydrogen Energy, vol. 38, no. 3, pp. 1636-1643, 2013.

[19] F. He, Z. Li, P. Liu, L. Ma, and E. N. Pistikopoulos, "Operation window and part-load performance study of a syngas fired gas turbine," Appl. Energy, vol. 89, no. 1, pp. 133-141, 2012.

[20] H.-Y. Shih and J.-R. Hsu, "A computational study of combustion and extinction of opposed-jet syngas diffusion flames," Int. J. Hydrogen Energy, vol. 36, no. 24, pp. 15868-15879, 2011.

[21] J. M. Beér and N. A. Chigier, "Combustion aerodynamics," New York, 1972.

[22] V. Tangirala, R. H. Chen, and J. F. Driscoll, "Effect of heat release and swirl on the recirculation within swirl-stabilized flames," Combust. Sci. Technol., vol. 51, no. 1-3, pp. 75-95, 1987.

[23] Y. Zhang, W. Shen, H. Zhang, Y. Wu, and J. Lu, "Effects of inert dilution on the propagation and extinction of lean premixed syngas/air flames," Fuel, vol. 157, pp. 115-121, 2015.

[24] D. E. Giles, S. Som, and S. K. Aggarwal, "NO x emission characteristics of counterflow syngas diffusion flames with airstream dilution," Fuel, vol. 85 , no. 12, pp. 1729-1742, 2006.

[25] Glassman, Yetter - 2010 - Unknown - Combustion.

[26] T. Garc'lia-Armingol and J. Ballester, "Operational issues in premixed combustion of hydrogen-enriched and syngas fuels," Int. J. Hydrogen Energy, vol. 40, no. 2, pp. 1229-1243, 2015.

[27] F. K. Owen, L. J. Spadaccini, and C. T. Bowman, "Pollutant formation and energy release in confined turbulent diffusion flames," in Symposium (International) on Combustion, vol. 16, no. 1, pp. 105-117, 1977. 